\title{
Killing of Histoplasma capsulatum by $\gamma$-interferon- activated human monocyte-derived macrophages: evidence for a superoxide anion-dependent mechanism
}

\author{
E. BRUMMER*, N. KURITA, S. YOSHIDA, KAZUKO NISHIMURA and M. MIYAJI
}

Research Center for Pathogenic Fungi and Microbial Toxicoses, Chiba University, 1-8-1 Inohana, Chiba, Japan

\begin{abstract}
Summary. The interaction of human macrophages with the yeast form of the thermally dimorphic fungal pathogen, Histoplasma capsulatum, was studied. Macrophages derived from monocytes by culture in vitro for 3 days ingested $H$. capsulatum, but were neither fungicidal or fungistatic. In contrast, when monocytes were exposed to human recombinant gamma-interferon ( $\gamma$-IFN) during their differentiation into macrophages, those macrophages were able to reduce the number of ingested or adherent cfu of $H$. capsulatum by $44-75 \%$ in $2 \mathrm{~h}$. Activation of macrophages for fungicidal activity by $\gamma$-IFN was dose dependent and 500-1000 units ml were optimal. Antibody to $\gamma$-IFN abrogated the $\gamma$-IFN activation process. Killing of $\boldsymbol{H}$. capsulatum by activated macrophages in 2-h assays could be inhibited by superoxide dismutase but not by sodium azide.
\end{abstract}

\section{Introduction}

Histoplasma capsulatum, a thermally dimorphic fungal pathogen, is the causative agent of histoplasmosis in man. ${ }^{1}$ Infection is established by inhalation of conidia from the soil-inhabiting saprophytic mycelial stage. In the lungs, conidia transform into the parasitic yeast form causing disease that ranges from benign, to chronic cavitating, or to disseminated infections. $^{2}$ Reactivation of previously controlled histoplasmosis has recently become a serious problem in patients with the acquired immunodeficiency syndrome (AIDS). ${ }^{3,4}$

To define a possible role for human macrophages in histoplasmosis, we have studied the interaction, in the presence or absence of human recombinant gammainterferon $(\gamma$-IFN), of macrophages derived from monocytes and $H$. capsulatum in vitro. Co-culture techniques developed for the study of human macrophages and Blastomyces dermatitidis were used. ${ }^{5}$

\section{Materials and methods}

\section{Monocyte-derived macrophages}

Peripheral blood mononuclear cells (PBMC) were isolated from heparinised $(10 \mathrm{U} / \mathrm{ml})$ blood of healthy human donors without histories of histoplasmosis. Standard methods, as previously described, were

Received 5 June 1990; revised version accepted 20 Oct. 1990.

* Correspondence should be sent to: Dr E. Brummer, Division of Infectious Diseases, Department of Medicine, Santa Clara Valley Medical Center, 751 S. Bascom Avenue, San Jose, CA 95128, USA. used. ${ }^{5}$ Monocytes in PBMC were selected by adherence to plastic or glass during incubation at $37^{\circ} \mathrm{C}$ for $2 \mathrm{~h}$ in an atmosphere of $\mathrm{CO}_{2} 5 \%$ in air. Complete tissue culture medium (CTCM) consisted of RPMI1640 (Gibco Laboratories, Long Island, NY, USA) containing penicillin $100 \mu / \mathrm{ml}$, streptomycin 100 $\mu / \mathrm{ml}$, and fresh autologous serum $15 \%$. Briefly, $0 \cdot 2 \mathrm{ml}$ of a suspension of PBMC $3 \times 10^{6} / \mathrm{ml}$ in CTCM, was dispensed into each well of flat-bottomed 96-well microtitration plates. After incubation, non-adherent cells were removed by aspiration and each well was washed once. The number of adherent cells was calculated by subtracting the mean number of nonadherent cells in each well from the original number of cells per well. Approximately $19 \%$ of PBMC were adherent to plastic, i.e., $1 \cdot 2 \times 10^{5}$ per well, and, as was shown previously, $90 \%$ were esterase positive. ${ }^{5}$ For experiments with Lab-Tek chamber slides (Nunc, Inc., Naperville, IL, USA), $0.25 \mathrm{ml}$ of a suspension containing PBMC $3 \times 10^{6} \mathrm{ml}$ was dispensed into each chamber. Adherent cells were selected and characterised as above.

\section{Treatment of monocytes}

Quadruplicate wells of adherent PBMC were cultured in CTCM or CTCM containing increasing concentrations of human recombinant $\gamma$-IFN (Collaborative Research Inc., Bedford, MA, USA). After incubation for 3 days at $37^{\circ} \mathrm{C}$ in air $+\mathrm{CO}_{2} 5 \%$, culture supernates were aspirated and monolayers of monocyte-derived macrophages were tested for fungicidal or fungistatic activity against $\boldsymbol{H}$. capsulatum. 


\section{H. capsulatum}

A well characterised isolate of $H$. capsulatum, CDC 105 (serotype 1,4 and chemotype 2), was used. The major wall component of this isolate consisted of $\alpha-1,3$ glucan. ${ }^{6}$ H. capsulatum was grown on brain heart infusion (BHI) agar slants at $37^{\circ} \mathrm{C}$. Fresh growth (3-4 days) was collected and washed with phosphatebuffered saline (PBS), and fungal units were counted in a haemocytometer. Quantitation of the inoculum according to morphology of fungal units showed that $41 \%$ SD $1 \%$ were one-cell units, $34 \%$ SD $5 \%$ were units with two cells, $11 \%$ SD $4 \%$ had three cells per unit, $7 \%$ SD $4 \%$ had four cells per unit, and $7 \%$ SD $2 \%$ consisted of units with five or more cells. The medium for cfu determinations by plating was that described by Schaffner et al., ${ }^{7}$ except that sheep blood $10 \%$ was substituted for rabbit blood in the BHI agar plates. Preliminary experiments showed that $85 \%$ of the fungal units, as determined by haemocytometer counting, were recovered as $\mathrm{cfu}$ with this medium.

\section{Fungicidal assay}

After the 3-day treatment period, macrophage monolayers were challenged with $\boldsymbol{H}$.capsulatum, $0.2 \mathrm{ml}$ of a suspension containing 10000 fungal units per ml of CTCM. After $2 \mathrm{~h}$ at $37^{\circ} \mathrm{C}$ in air $+5 \% \mathrm{CO}_{2}$, non-adherent $H$. capsulatum cells were aspirated and the monolayers were rinsed with $0.2 \mathrm{ml}$ of CTCM. Aspirated + rinse material were cultured to determine the number of non-adherent cfu. Monolayers with ingested $H$. capsulatum were harvested with distilled water to lyse macrophages as previously described. ${ }^{5}$ From harvested material, $1 \mathrm{ml}$ per culture was plated to each BHI blood-agar plate. Plates were incubated for 2 days at $37^{\circ} \mathrm{C}$, placed in plastic containers to prevent dehydration, and incubated for 5 more days at $37^{\circ} \mathrm{C}$. The numbers of cfu/plate were recorded and $\mathrm{cfu} /$ culture were calculated. Since there were no significant differences between the numbers of nonadherent cfu of $H$. capsulatum cultured from monolayers treated .with CTCM or $\gamma$-IFN, the number of adherent or ingested cfu in control and experimental monolayers were equivalent. Based on this, the percentage killing was determined by the formula: [1-(cfu from experimental cultures/cfu from control cultures) $] \times 100$.

\section{Assessment of ingestion and adherence}

Duplicate macrophage monolayer cultures that had been established in Lab-Tek chambers were challenged with $H$. capsulatum $(0.25 \mathrm{ml}$ of a suspension containing 10000 fungal units $/ \mathrm{ml}$ of CTCM) in a calculated ratio of macrophage to $\boldsymbol{H}$. capsulatum of $1: 10$. After $2 \mathrm{~h}$ at $37^{\circ} \mathrm{C}$ in $\mathrm{CO}_{2} 5 \%$ in air, monolayers were washed with PBS, dried, and stained with Wright's stain. Macrophages were examined micro- scopically and the percentage of ingestion + adherence was determined by the formula: (number of macrophages with ingested $H$. capsulatum/number of macrophages examined) $\times 100 ; 100$ macrophages in each duplicate monolayer were examined (total $=200$ ).

\section{Anti- $\gamma$-IFN antibody}

Rabbit antibody to affinity column purified natural human $\gamma$-IFN (Genzyme Corporation, Boston, MA, USA) was used to neutralise human recombinant $\gamma$ IFN. Anti- $\gamma$-IFN antibody was added to quadruplicate cultures of $\gamma$-IFN-treated monocyte monolayers or control cultures at the beginning of the treatment period.

\section{Scavengers and inhibitors}

Superoxide dismutase (SOD) $(11500 \mathrm{U} / \mathrm{mg}$ of protein; Seikagaku Kogyo Co., Ltd, Tokyo, Japan) was dialysed against PBS, sterilised by membrane filtration $(0.45-\mu \mathrm{m}$ pore size $)$ and stored at $4^{\circ} \mathrm{C}$. A portion of the SOD preparation was inactivated by autoclaving $\left(121^{\circ} \mathrm{C}, 30 \mathrm{~min}\right)$. Sodium azide $(0.01 \mathrm{M}$ in PBS) was sterilised by filtration as above and stored at $4^{\circ} \mathrm{C}$. SOD, heat-inactivated SOD, or sodium azide were added at the same time as the $H$. capsulatum challenge to macrophage cultures.

\section{Lab-Tek cultures}

As in phagocytosis studies, duplicate monocytederived macrophage cultures were established for determination of killing as measured by reduction of numbers of cfu of ingested or adherent $H$. capsulatum. For these experiments, and those in which an attempt was made to follow intracellular replication by microscopic examination, the macrophage to H. capsulatum ratio was $33: 1$.

\section{Direct counts}

To control for possible variation, e.g., clumping, in the composition of fungal units in control $v s$ experimental cultures, direct examination of plated material was made with a haemocytometer as previously described. ${ }^{5}$ When pooled, pelleted, harvested material in $0.025 \mathrm{ml}$ was counted with a haemocytometer, it was possible to estimate the number of fungal units and, at the same time, record the morphology of fungal units.

\section{Statistical analysis}

Comparison between groups was made by Student's $t$-test with the level of significance considered to be $\mathrm{p}<0 \cdot 05$. 


\section{Results}

\section{Dose requirement for $\gamma$-IFN activation of macrophages}

When monocytes were cultured for 3 days in higher concentrations of $\gamma$-IFN, i.e. 500 and $1000 \mathrm{U} / \mathrm{ml}$, they became activated and they significantly reduced the number of cfu of ingested or adherent $H$. capsulatum (table I). Treatment with $\gamma$-IFN $250 \mathrm{U} / \mathrm{ml}$ did not activate macrophages to significantly reduce the inoculum number of cfu of ingested $H$. capsulatum (table I). All the macrophage monolayers were challenged with the same inoculum for $2 \mathrm{~h}$. When the noningested or non-adherent numbers of $\mathrm{cfu}$ of H. capsulatum were determined by plating, they were not significantly different, e.g., with CTCM alone (control) 384 SD 26 with $\gamma$-IFN $250 \mathrm{U} / \mathrm{ml} 423$ SD 19, $500 \mathrm{U} / \mathrm{ml} 361 \mathrm{SD} 43,1000 \mathrm{U} / \mathrm{ml} 397 \mathrm{SD} 41$. Therefore, the number of $H$. capsulatum cfu that were ingested or adherent in all of the co-cultures were equivalent. Since $54-58 \%$ fewer cfu were recovered from cultures containing activated macrophages, this reduction of recoverable cfu was interpreted as killing (table I). This interpretation was supported by elimination of other possible explanations. For example, microscopic examination of harvested culture wells showed that the harvesting procedure removed all well contents equally, and direct microscopy of harvested material showed that the average number of cells per fungal unit was equivalent in the material from different cultures ( $2-3$ cells/unit). Therefore, neither adherence of $H$. capsulatum cells to experimental culture wells nor clumping of the yeast cells was an explanation for the reduction in numbers of $\mathrm{cfu}$.

Similar results were obtained when macrophages were tested in Lab-Tek chambers instead of microtest plate wells. Macrophages derived in the presence of $\gamma$ IFN $1000 \mathrm{U} / \mathrm{ml}$ reduced the number of ingested or adherent cfu of $H$. capsulatum by $51 \%$ compared to control macrophages (4000 SD 900 vs 8100 SD 1900). Non-adherent numbers of cfu of control and experimental cultures were not significantly different.

\section{Inoculum size and killing of $H$. capsulatum by activated macrophages}

In different experiments the inoculum size varied; consequently the number of cfu ingested or adherent to macrophages varied. Within the range tested $(240$ SD 20-740 SD 140) the percentage killing (44-58\%) of $H$. capsulatum by the constant size $\gamma$-IFN (1000 U/ $\mathrm{ml}$ )-activated macrophage monolayers was not significantly changed (table II).

\section{Abrogation of activated macrophage killing}

The fungicidal mechanism of activated macrophages for $H$. capsulatum was investigated by the use of superoxide anion scavenger, SOD, and an inhibitor
Table I. Effect of $\gamma$-IFN concentrations on activation of macrophages

\begin{tabular}{ccc}
\hline $\begin{array}{c}\text { Treatment } \\
\text { of macrophages }\end{array}$ & $\begin{array}{c}\text { Mean cfu (SD) of } \\
\text { ingested or adherent } \\
\text { H. capsulatum } \\
(\mathrm{n}=4)\end{array}$ & $\begin{array}{c}\text { Percentage killing } \\
\text { compared to control }\end{array}$ \\
\hline CTCM (control) & $240(20)$ & $\ldots$ \\
$\gamma$-IFN 250 U/ml & $200(10)$ & $17 \%^{*}$ \\
$\gamma$-IFN 500 U/ml & $110(20)$ & $54 \%^{*}$ \\
$\gamma$-IFN 1000 U/ml & $100(20)$ & $58 \%^{*}$ \\
\hline
\end{tabular}

$* \mathrm{p}<0 \cdot 001$.

of the myeloperoxidase enzyme, sodium azide. SOD $500 \mathrm{U} / \mathrm{ml}$, which did not affect ingestion of $H$. capsulatum by macrophages, inhibited the killing of $\boldsymbol{H}$. capsulatum by $\gamma$-IFN activated macrophages $(0 \%$ vs $50 \%$ ) (table III). Heat-inactivated SOD had no effect on killing. However, $1 \mathrm{~mm}$ azide had no effect on $\gamma$-IFN activated macrophage killing of $\boldsymbol{H}$. capsulatum (table III). These results indicate that superoxide anion, a product of the oxidative burst, was required for the fungicidal activity, whereas the myeloperoxidase- $\mathrm{H}_{2} \mathrm{O}_{2}$-halide system was not involved.

\section{Neutralisation of $\gamma$-IFN activation by anti- $\gamma-I F N$}

Specific antibody to $\gamma$-IFN, present during the treatment period, completely blocked the activation of monocyte-derived macrophages for killing H. capsulatum (fig. 1). There were significantly ( $<<$ $0.001)$ fewer cfu $(44 \%)$ recoverable from $\gamma$-IFNactivated macrophage cultures than from control, anti$\gamma$-IFN, or anti- $\gamma$-IFN $+\gamma$-IFN cultures after $2 \mathrm{~h}$

Table II. Effect of increasing numbers of $H$. capsulatum on macrophage killing

\begin{tabular}{ccc}
$\begin{array}{c}\text { Mean number (SD) of ingested or adherent } \\
\text { cfu after } 2 \mathrm{~h} \text { in cultures of macrophages } \\
\text { treated with }\end{array}$ & $\begin{array}{c}\text { Percentage killing by } \\
\gamma \text {-IFN-activated } \\
\text { macrophages }\end{array}$ \\
$\begin{array}{ccc}\text { CTCM (control) } \\
(\mathrm{n}=4)\end{array}$ & $\begin{array}{c}\gamma \text {-IFN } 1000 \mathrm{U} / \mathrm{ml} \\
(\mathrm{n}=4)\end{array}$ & \\
\hline $240(20)$ & $100(20)$ & $58 \% *$ \\
$495(80)$ & $280(10)$ & $4 \%^{*}$ \\
$740(140)$ & $360(20)$ & $52 \%^{*}$
\end{tabular}

* Percentage reduction of number of cfu in $\gamma$-IFN-treated compared to CTCM-treated (control) macrophages.

Table III. Effect of SOD or azide on fungicidal activity of activated macrophages

\begin{tabular}{lccc}
\hline $\begin{array}{c}\text { Treatment } \\
\text { of macrophages }\end{array}$ & $\begin{array}{c}\text { Inhibitor } \\
\text { added with } \\
\text { challenge }\end{array}$ & $\begin{array}{c}\text { Mean cfu (SD) of } \\
\text { ingested or adher- } \begin{array}{c}\text { Percentage } \\
\text { killing in } 2 \mathrm{~h}\end{array} \\
\text { compapsulatum } \\
(\mathrm{n}=4)\end{array}$ & $\begin{array}{c}\text { compared to } \\
\text { control (\%) }\end{array}$ \\
\hline CTCM (control) & $\ldots$ & $465(35)$ & $\ldots$ \\
$\gamma$-IFN $1000 \mathrm{U} / \mathrm{ml}$ & $\ldots$ & $235(10)$ & 50 \\
$\gamma$-IFN $1000 \mathrm{U} / \mathrm{ml}$ & SOD & $470(40)$ & 0 \\
$\gamma$-IFN $1000 \mathrm{U} / \mathrm{ml}$ & Azide & $240(25)$ & 49 \\
\hline
\end{tabular}




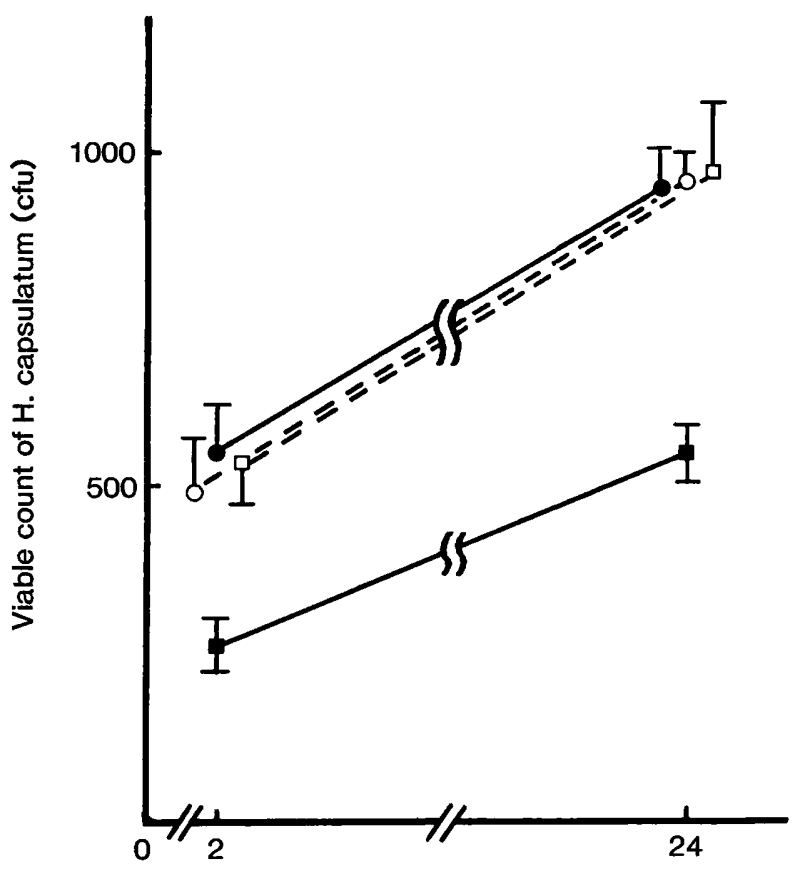

Time (h)

Fig. 1. Effect of $\gamma$-IFN, antibody to $\gamma$-IFN, and time on activity of macrophages is $\mathrm{H}$. capsulatum. Antifungal activity of monocytes treated for 3 days with CTCM $(\mathrm{O}-\mathrm{O})$, antibody to $\gamma$-IFN (O), $\gamma$-IFN + antibody to $\gamma$-IFN ( $\square-\square)$, or $\gamma$-IFN $1000 \mathrm{U} / \mathrm{ml}$ (覀) after $2 \mathrm{~h}$ of interaction with $\boldsymbol{H}$. capsulatum. Growth of ingested $H$. capsulatum from 2 to $24 \mathrm{~h}$ is also shown for the four types of macrophage monolayers.

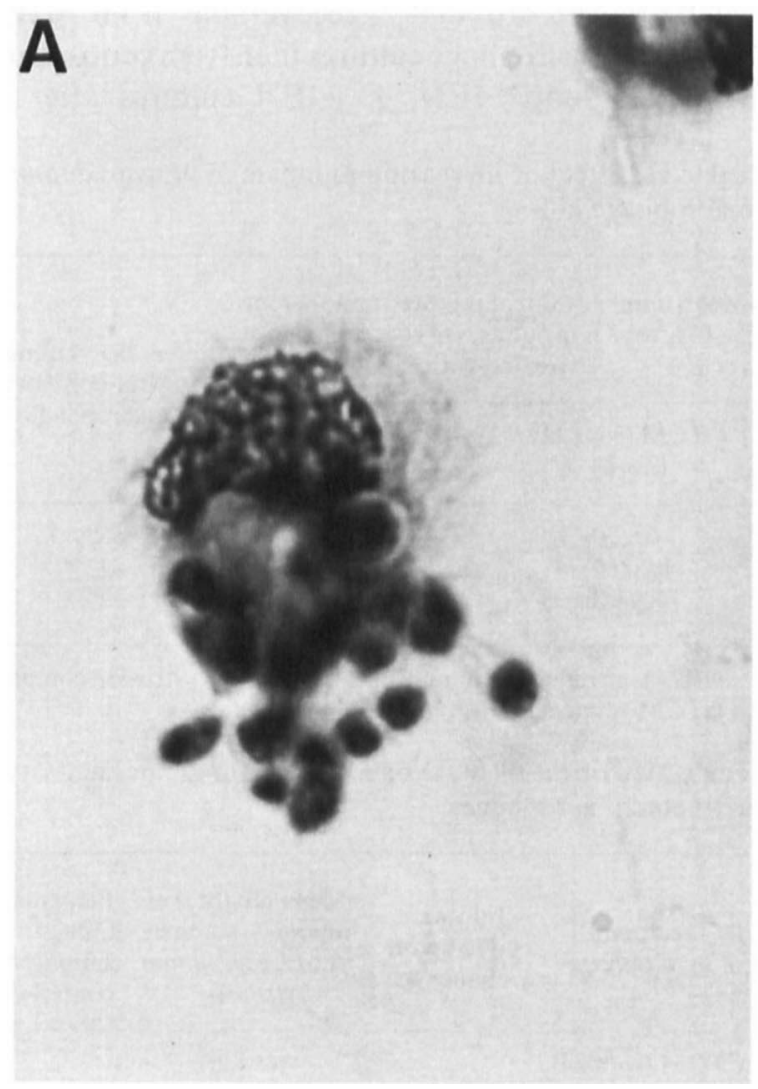

(fig. 1). The numbers of cfu non-adherent to control and experimental cultures were not significantly different. The time zero inoculum was the same for all cultures.

\section{Effect of culture time}

When cultures parallel to those harvested at $2 \mathrm{~h}$, which would contain the same number of cfu, were incubated for another $22 \mathrm{~h}$, the cfu of $H$. capsulatum that survived the initial killing by activated macrophages were able to replicate at approximately the same rate as those in control macrophage cultures (fig. 1). These findings show that, under these conditions, activated macrophages were not fungistatic.

\section{Combined ingestion and adherence}

In ingestion assays, in which the $H$. capsulatum to macrophage ratio was 10:1, each macrophage could engulf or attach many yeast cells (fig. 2, A and B). There was no significant difference in the percentage of control macrophages ingesting or attaching yeast cells $(88.5 \%)$ from that of $\gamma$-IFN $(250 \mathrm{U} / \mathrm{ml}, 94 \% ; 500$ $\mathrm{U} / \mathrm{ml}, 93.5 \% ; 1000 \mathrm{U} / \mathrm{ml}, 95.5 \%$ ) -treated macrophages. Heterogeneity of $\gamma$-IFN $(500 \mathrm{U} / \mathrm{ml})$-activated macrophages is illustrated in fig. 2 . In fig. $2 \mathrm{~A}$ a macrophage with a large spongy nucleus is shown. In fig. 2B a macrophage with a compact kidneyshaped nucleus can be seen.

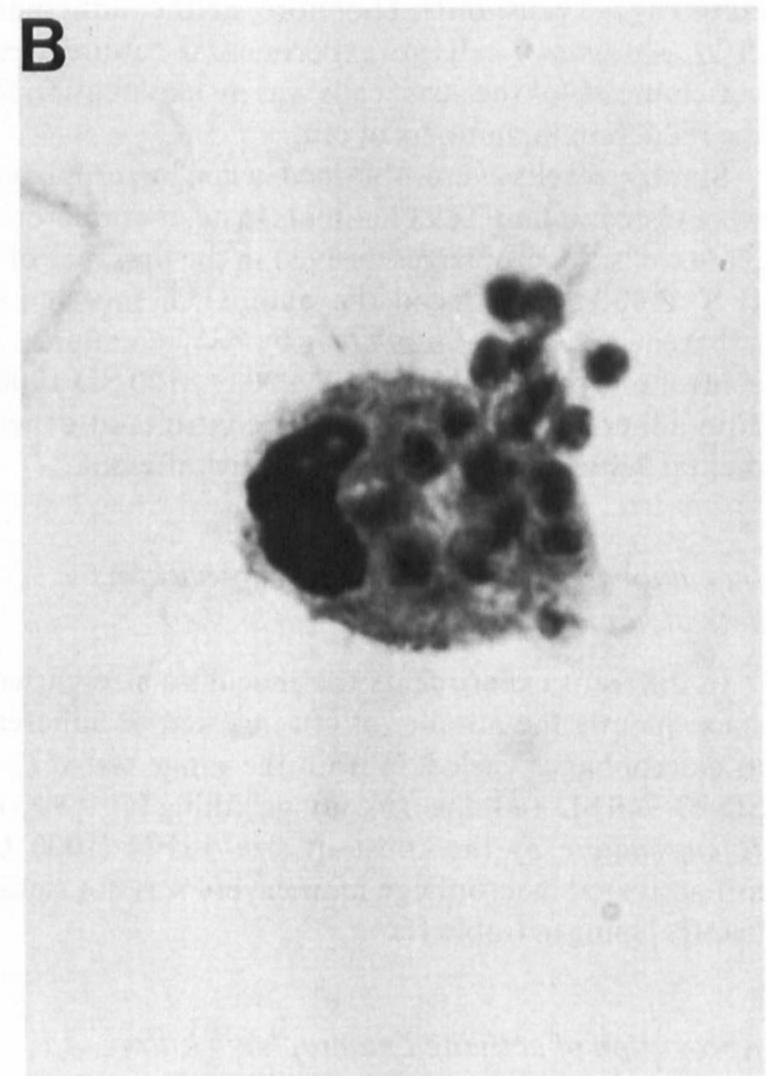

Fig. 2. Combined ingestion and attachment of $H$. capsulatum by $\gamma-\mathrm{IFN}(500 \mathrm{U} / \mathrm{ml})$-activated macrophages. (A) Ingestion and attachment of H. capsulatum yeast cells by an activated macrophage with a spongy nucleus. (B) An activated macrophage with a compact kidney shaped nucleus with ingested and attached yeast cells. 


\section{Heterogeneity in macrophage monolayers}

When an adherent population of monocytes differentiated into macrophage-like cells during culture in CTCM, a range of morphologies were seen (fig. 3A). About $50 \%$ of the cells showed enhanced spreading, but only $17 \%$ showed spindle formation and one macrophage exhibited a spongy-type nucleus (fig. 3A). Monocytes that had differentiated in the presence of $\gamma$-IFN $(1000 \mathrm{U} / \mathrm{ml})$ also showed some heterogeneity in morphology (fig. 3B). A noticeable increase in spreading and enhanced spindle formation was exhibited by $38.9 \%$ of the cells shown, whereas the other cells remained compact.

\section{Discussion}

We report here the novel finding that $\gamma$-IFNactivated macrophages were fungicidal for $H$. capsulatum in vitro. The significance of induction of fungicidal activity in macrophages by $\gamma$-IFN relates to basic understanding of host defence mechanisms against this facultative intracellular pathogen as well as potential immunotherapeutic strategies.

Our findings help clarify the possible role of human macrophages in controlling this infective agent. A recent study suggested that intracellular replication of $H$. capsulatum was unaffected in $\gamma$-IFN-activated macrophages, ${ }^{8}$ thus implying that activated macro-

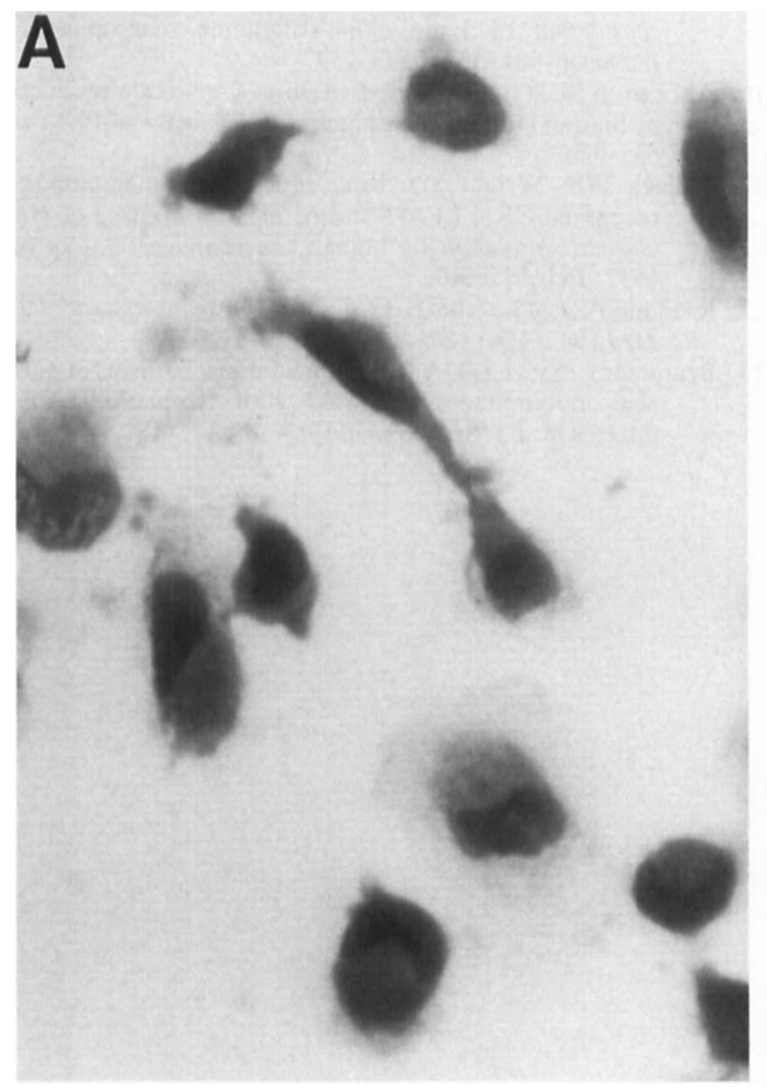

phages probably do not have a protective role. However, the protocols and techniques used in those experiments were those used previously with murine macrophages $^{9}$ (e.g., following microscopically the number of ingested yeast cells per macrophage with time, starting after the 2-h ingestion period), and were unable to detect the fungicidal activity of activated macrophages during the ingestion period, as reported here. By using a culture methodology, we were able to demonstrate killing of $H$.capsulatum during the ingestion period which would go undetected by the microscopy technique.

Observations made by us after the 2-h ingestion period by culture methodology agreed with those reported by Fleishmann $e t$ al. ${ }^{8}$ who used microscopysurviving yeast cells replicated in activated macrophage monolayers. These results differ from those obtained with murine macrophages; e.g., murine peritoneal macrophages treated with lymphokines restricted the intracellular growth of ingested H. capsulatum. ${ }^{9}$ The assumption that all macrophages in monolayers were activated may not be justified. We noticed that macrophage monolayers were not homogenous; some $\gamma$-IFN-treated adherent cells remained rounded whereas others exhibited spreading. Heterogeneity of macrophage monolayers may be a possible explanation for the survival and replication of some yeast cells, which might occur if they were ingested by a subpopulation of macrophages in the monolayer.

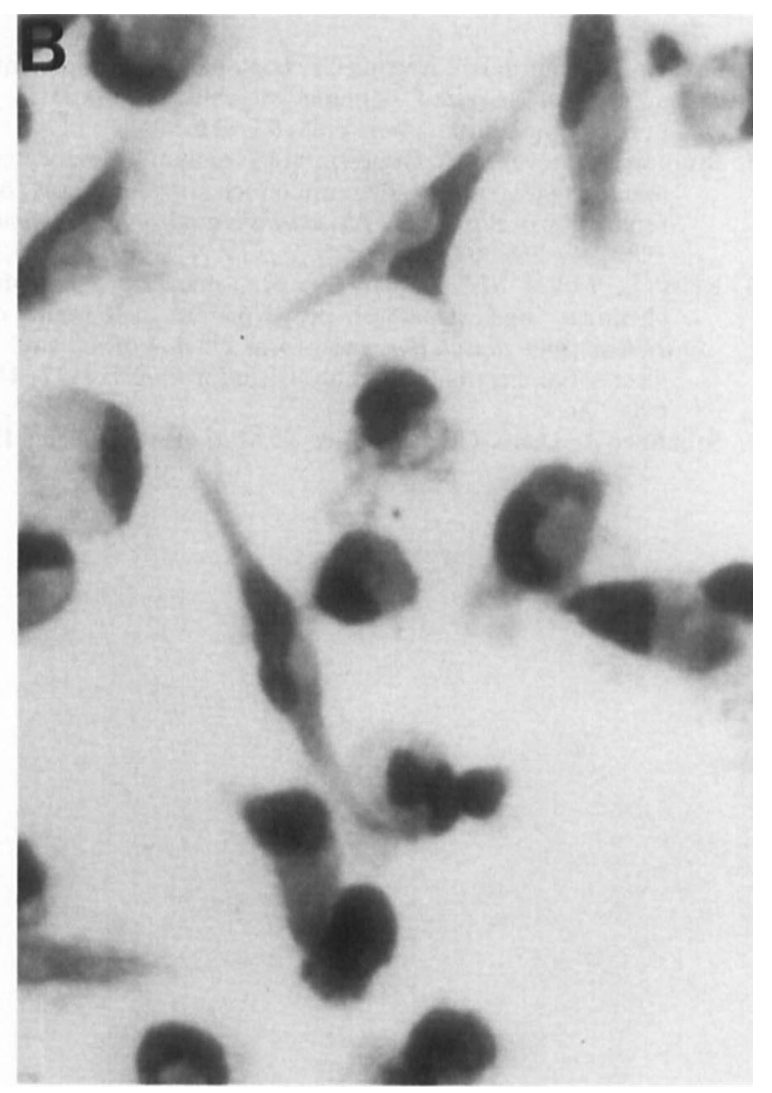

Fig. 3. Macrophage monolayers. (A) Monocytes which differentiated into macrophage-like cells during culture in CTCM. (B) Monocytes cultivated in the presence of IFN $1000 \mathrm{U} / \mathrm{ml}$. 
The importance of a role for activated macrophage killing of $H$. capsulatum in host resistance is magnified because polymorphonuclear neutrophils are not fungicidal for $H$. capsulatum in vitro in short-term assays? (and unpublished results). Therefore, the production of $\gamma$-IFN during infection and its influence on either differentiated macrophages or monocytes differentiating under the influence of $\gamma$-IFN, could be a crucial factor in host resistance to $H$. capsulatum. These considerations are relevant to recent reports of reactivation of previously controlled histoplasmosis in patients suffering from AIDS $^{3,4}$ and they suggest possible immunotherapeutic strategies.

Our first report here for a fungicidal mechanism against $H$. capsulatum in human phagocytes is significant because it increases our understanding of how $H$. capsulatum can be killed. Although non-activated macrophages ingesting $H$. capsulatum have been reported to generate superoxide anion as measured by nitroblue tetrazolium reduction, ${ }^{11}$ such levels apparently are not sufficient for killing $H$. capsulatum. The dependence of this fungicidal mechanism on certain levels of superoxide anion coincides with the well

\section{References}

1. DeMonbreun WA. The cultivation and cultural characteristics of Darling's Histoplasma capsulatum. Am J Trop Med 1934; 14: 93-125.

2. Schwartz J. The pathogenesis of histoplasmosis. Trans $N Y$ Acad Sci 1958; 20: 541-548.

3. Graybill JR. Histoplasmosis and AIDS. J Infect Dis 1988; 158: 623-626.

4. Salzman SH, Smith RL, Aranda CP. Histoplasmosis in patients at risk for acquired immunodeficiency syndrome in a nonendemic setting. Chest 1988; 93: 916-921.

5. Brummer E, Stevens DA. Opposite effects of human monocytes, macrophages, and polymorphonuclear neutrophils on replication of Blastomyces dermatitidis in vitro. Infect Immun $1982 ; 36$ : 297-303.

6. Reiss E, Miller SE, Kaplan W. Kaufman L. Antigenic, chemical, and structural properties of cell walls of Histoplasma capsulatum yeast-form chemotypes 1 and 2 after serial enzymatic hydrolysis. Infect Immun 1977; 16: 690-700.

7. Schaffner A, Davis CE, Schaffiner T, Market M, Douglas H, documented enhanced production of superoxide anion by macrophages derived from monocytes in the presence of $\gamma$-IFN $1000 \mathrm{U} / \mathrm{ml},{ }^{10}$ and suggests that the Fenton as well as the Haber-Weiss reaction may be involved. Klebanoff ${ }^{12}$ has described how superoxide anion reacting with $\mathrm{H}_{2} \mathrm{O}_{2}$, or when reacting ferric iron generates ferrous iron used in the Fenton reaction $\left(\mathrm{Fe}^{+2}+\mathrm{H}_{2} \mathrm{O}_{2} \rightarrow \mathrm{Fe}^{+3} \mathrm{OH}^{-}+\mathrm{OH}^{-}\right)$, generates hydroxyl radicals.

We have reported previously on superoxide aniondependent fungicidal mechanisms involved in killing of Candida parapsilosis by normal murine peritoneal macrophages and the killing of Candida albicans by $\gamma$ IFN-activated murine peritoneal macrophages. ${ }^{13}$ In both cases, and in the present report, SOD $450 \mathrm{U} / \mathrm{ml}$ abrogated killing. Taken together, these results and the present report document the existence of a superoxide anion-dependent fungicidal mechanism in macrophages which remains to be elucidated.

During the course of these studies E.B. was supported by the Japanese Ministry of Education as a guest professor-foreign researcher at Chiba University Research Center for Pathogenic Fungi and Microbial Toxicoses.
Braude A I. In vitro susceptibility of fungi to killing by neutrophil granulocytes discriminates between primary pathogenicity and opportunism. J Clin Invest 1986; 78: 511-524.

8. Fleischmann J, Wu-Hsieh B, Howard DH. The intracellular fate of Histoplasma capsulatum in human macrophages is unaffected by recombinant human interferon $-\gamma$. $J$ Infect Dis 1990 ; 161 : 143-145.

9. Wu-Hsieh B, Howard DH. Inhibition of growth of Histoplasma capsulatum by lymphokine-stimulated macrophages. $J$ Immunol 1984; 132: 2593-2597.

10. Abramson SL, Gallin JI. IL-4 inhibits superoxide production by human mononuclear phagocytes. J Immunol 1990; 144 : 625-630.

11. Bullock WE, Wright SD. Role of the adherence-promoting receptors, CR3, LFA-1 and p150,95 in binding of Histoplasma capsulatum by human macrophages. J Exp Med 1987; 165: 195-210.

12. Klebanoff SJ. The iron- $\mathrm{H}_{2} \mathrm{O}_{2}$-iodide cytotoxic system. $J$ Exp Med 1982; 156: 1262-1267.

13. Brummer E, Stevens DA. Candidacidal mechanisms of peritoneal macrophages activated with lymphokines or $\gamma$ interferon. J Med Microbiol 1989; 28: 173-181. 